\title{
Frontiers
}

\section{in the Psychotherapy} of Trauma \& Dissociation

\section{Working From the Adult Self} Anabel González, MD, PhD

The Official Clinical Journal of the International Society for the Study of Trauma and Dissociation 


\title{
Frontiers in the Psychotherapy of Trauma \& Dissociation
}

The Official Clinical Journal of the ISSTD

\section{EDITOR}

ANDREAS LADDIS, MD, Private Practice and Faculty, Boston University, School of Public Health, Boston, Massachusetts, USA

\author{
ASSOCIATE EDITOR \\ MARTIN J DORAHY, PhD, Professor, Department of Psychology, University of Canterbury, \\ Christchurch, New Zealand and The Cannan Institute, Brisbane, Australia
}

\section{EDITORIAL ASSISTANT}

COURTENAY CRUCIL, MA, RCC, Private Practice, Terrace, British Columbia, Canada

\begin{abstract}
Frontiers in the Psychotherapy of Trauma $\mathcal{E}$ Dissociation is published by the International Society for the Study of Trauma and Dissociation, Inc., 4201 Wilson Blvd Third Floor, Arlington, VA 22203
\end{abstract}

\section{Annual Subscription, Volume 4, 2020}

Online subscription is part of the membership dues of the International Society for the Study of Trauma and Dissociation. Visit https://www.isst-d.org/join-isstd/individualmember-benefits/.

Production and Advertising Office: ISSTD Headquarters, 4201 Wilson Blvd Third Floor, Arlington, VA 22203

Copyright $\odot 2020$ International Society for the Study of Trauma and Dissociation. All rights reserved. No part of this publication may be reproduced, stored, transmitted, or disseminated in any for or by any means without prior written permission from the International Society for the Study of Trauma and Dissociation. The publisher assumes no responsibility for any statements of fact or opinion expressed in the published papers. The appearance of advertising in this journal does not constitute an endorsement or approval by the publisher, the editor, the editorial board, or the board of directors of the International Society for the Study of Trauma and Dissociation of the quality or value of the product advertised or of the claims made of it by its manufacturer.

Subscriptions to this journal are acquired through membership in the International Society for the Study of Trauma and Dissociation only.

Visit https://www.isst-d.org/join-isstd/individual-memberhip-categories/.

Permissions. For further information, please write to info@isst-d.org.

\section{EDITORIAL BOARD}

ELIZABETH S BOWMAN, MD, Editor Emerita, Journal of Trauma \& Dissociation, Adjunct Professor of Neurology, Indiana University School of Medicine, Indianapolis, Indiana, USA

LAURA S. BROWN, PhD, Private Practice, Seattle, Washington, USA

RICHARD A CHEFETZ, MD, Private Practice, Faculty and Founding Member Institute of Contemporary Psychotherapy \& Psychoanalysis, Distinguished Visiting Lecturer: William Alanson White Institute of Psychiatry, Psychoanalysis \& Psychology, New York City, USA

CONSTANCE J DALENBERG, PhD, Trauma Research Institute, California School of Professional Psychology, San Diego, California, USA

J.K. JUDITH DANIELS, PhD, Faculty of Behavioural and Social Sciences, University of Groningen, The Netherlands

STEVEN N GOLD, PhD, Professor, Center for Psychological Studies, and Founding Director, Trauma Resolution \& Integration Program, Nova Southeastern University, Fort Lauderdale, Florida, USA ELIZABETH B HEGEMAN, PhD, Professor, Department of Anthropology, John Jay College of Criminal Justice, New York, New York, USA 
RICHARD P. KLUFT, MD, PhD Private Practice and Clinical Professor of Psychiatry, Temple University School of Medicine; Faculty Member, Philadelphia Center for Psychoanalysis,

Philadelphia, Pennsylvania, USA

CHRISTA KRÜGER, MD, Professor of Psychiatry, University of Pretoria, Pretoria, Gauteng, South Africa

KARLEN LYONS-RUTH, PhD, Professor of Psychology, Harvard Medical School, Cambridge, Massachusetts, USA

ALFONSO MARTÍNEZ-TABOAS, PhD, Professor, Albizu University, San Juan, Puerto Rico WARWICK MIDDLETON, MD, Adjunct Professor, Cannan Institute, Brisbane, Australia

ELLERT R. S. NIJENHUIS, PhD, Department of Psychiatry and Outpatient Department Mental Health Care Drenthe, Assen, The Netherlands

SANDRA PAULSEN, PhD, Bainbridge Institute for Integrative Psychology, Bainbridge Island, Washington, USA

VEDAT SAR, MD, Professor of Psychiatry, Koç University School of Medicine (KUSOM), Istanbul, Turkey

JOYANNA SILBERG, PhD, Trauma Disorders Program, Sheppard Pratt Health Systems, Baltimore, Maryland, USA

ELI SOMER, PhD, Professor, School of Social Work, University of Haifa, Israel

KATHY STEELE, MN, CS, Private Practice, Atlanta, Georgia, USA

ONNO VAN DER HART, PhD Emeritus Professor of Psychopathology of Chronic Traumatization, Department of Clinical and Health Psychology, Utrecht University, Utrecht, The Netherlands VICTOR WELZANT, PsyD, Sheppard Pratt Health Systems, Trauma Disorders Program

\section{REVIEWERS}

JOHN BRIERE, PhD, Associate Professor of Psychiatry and Psychology, University of Southern California Keck School of Medicine, Los Angeles, California, USA

SHELDON IZKOWITZ, PhD, Clinical Associate Professor of Psychology and Clinical Consultant, Postdoctoral Program, New York University, New York City, USA and Teaching Faculty \& Supervisor of Psychotherapy and Psychoanalysis, National Institute for Psychotherapies, New York City, USA

MARY-ANNE KATE, PhD Researcher at University of New England, Australia; University of New England, New South Wales, Australia

ULRICH F. LANIUS, PhD, Private Practice, West Vancouver, British Columbia, Canada

\section{SUPPORTERS}

ISSTD thanks its generous supporters whose contributions have made this publication possible:

Andreas Laddis, MD, USA

\section{The \\ Cannan \\ Institute}

Cannan Institute, Australia

Warwick Middleton, MD, Australia

Dana Ross, MD, Canada

Martin J. Dorahy, PhD, New Zealand

Kate McMaugh, Australia

Sara Y. Krakauer, USA

Paula Eagle, MD, USA 


\section{ARTICLE \\ WORKING FROM THE ADULT SELF

\author{
ANABEL GONZÁLEZ, MD, PhD \\ Hospital Marítimo de Oza, A Coruña, Spain
}

The way severely traumatized people take care of themselves, both internally and in relationships, is deeply disturbed. The dysfunctional patterns of taking care of themselves that they learned as dependents persist beyond the situations that generated them. Dysfunctional self-care may influence the patient's attitude towards getting help and change in therapy. To change in therapy, the person must work patiently on modifying these patterns. They need to actively participate in the transformation process. This article reflects on the complex topic of patients' responsibility and motivation for change in trauma-oriented psychotherapies. It presents a working model based on empowering the patient's adult self and proposes some practical interventions to work on promoting it.

KEYWORDS complex trauma; dissociative disorders; adult self; selfcare

\section{INTRODUCTION}

In trauma-oriented psychotherapy, we must work with individuals who present strong tendencies to avoid help, who do not adequately care for themselves in various ways: they are prone to self-harm, self-neglect, as well as self-defeating behaviors. These individuals may distrust the therapist, make unreasonable or unrealistic demands, or even block their own therapeutic process. Therapists may have learned very effective therapeutic tools, but all of these are useless when the patient does not participate in

Author Contact Information - Anabel González, MD, PhD; Complexo Hospitalario Universitario de A Coruña (CHUAC), Hospital Marítimo de Oza. Servicio de Psiquiatría, As Xubias, s/n, 15006 A Coruña, Spain, email: anabelgonzalez@outlook.com. 
the therapeutic process or seems to be against it. So, how can we help our patients engage in treatment? This paradox of needing help but rejecting it is very common in trauma survivors. If they have grown up in adverse environments, they did not learn healthy self-care patterns. They often do what is worse for them rather than what is best.

We need to help our patients be agents of their recovery, and this is frequently more challenging than our interventions can accomplish. Patients with severe attachment disturbances and early trauma often do not know what will help them. They lack healthy references of functioning, both internally and in their relationships. Trauma therapy usually needs to include an extended and deep psychoeducational component, but this is much more than giving them information about trauma and dissociation. Much of their learning is dysfunctional, and they need to unlearn this and get new information that is often difficult to assimilate, the results of which are puzzling to them, or incompatible with their core beliefs. Even the patient's commitment to the therapeutic process is complex because their attitude toward treatment is ambivalent. For example, it is difficult to work with people who do not attend their sessions for long periods of time, or with patients who do come but then struggle with us or make no effort to change in their real life.

The idea of working from the Adult Self is to encourage our patients to take responsibility for their therapeutic process. When we treat severely dissociative patients or complex trauma cases with very dysfunctional personality traits, this is a necessary and challenging part of the treatment. A particularly problematic situation is when some of the dissociative parts can only be regulated with the therapist's intervention, while the patient does not fully participate in this labor. Dissociative child parts that suffered profound experiences of abandonment may try to receive from their therapist what they lack and hope to repair their earlier experiences. But this situation may devolve, resulting in an extreme dependency on the therapist, and without learning to self-regulate. In other cases, the patient may complain about other people or the entire world, searching for justice or a compensation for their suffering, but their situation will not change by just doing that. We need to help our patients commit to a legitimate therapeutic process, with a realistic, responsible and proactive approach. However, this is not easy in complex trauma, and it is important to work on motivation for change.

I developed the concept of the Adult Self in the book It's Not Me: Understanding Complex Trauma, Attachment and Dissociation (González, 2018). It is one main concept in how I carry out treatment. When I began working with complex trauma groups, I discovered that the actual content of the sessions was not the most complicated aspect of the work. Many patients were afraid to come to the group due to their tendency to distrust or because of their phobia of trauma. They missed many appointments because they had a 
strong tendency toward self-abandonment (self-harm is what the person does against themselves; self-abandonment is what they would need to do for themselves but do not do). Some patients would sit in a corner without participating in group discussions and without assimilating the information that we were sharing. And, even when they actively participated in the group sessions, their learnings from the group sessions were often not put to practice in their daily-life situations. So, I began to focus more on psychoeducation about why they would be very likely to come to treatment with helplessness and despair (Seligman, 1975), and how they could overcome all these tendencies. This approach led to more compliance with therapy sessions and more improvement in the majority of the participants.

Our patients need to understand why it is so difficult for them to take control over their problems. They need to become aware of their dysfunctional patterns and to also become aware of the steps that they can take to overcome them. This understanding goes beyond becoming aware of the different parts of the personality in dissociative identity disorder (DID). It extends to areas such as emotional regulation, self-care, attachment patterns and interpersonal difficulties, the meaning of dissociative symptoms, etc. Many severely traumatized people feel that recovery is not possible, that nobody is willing or able to help them, or they are waiting for a magical solution or for an omnipotent rescuer. They misread our therapeutic proposition from that perspective, and we must make it more explicit: we understand why they feel this way, why they do not adequately take care of themselves, but recovery is possible by taking a realistic path to achieve it.

\section{THE CONCEPT OF THE ADULT SELF}

The concept of the Adult Self was already included in the book EMDR and Dissociation: The Progressive Approach (Gonzalez \& Mosquera, 2012). The proposition there was to work with dissociative patients through the Adult Self that will be present all the time-if possible-during internal communication. This concept of the Adult Self resembles the Healthy Adult Mode from schema therapy (Young, Kloska, \& Weishaar, 2003), the adult part of the self that serves an "executive" function relative to the other modes. Young, Kloska and Weishaar (2003) state that severely disturbed patients usually have a weak adult mode and that the therapist should model or help them create this mode. For them, treatment played the function of a good parent.

A related concept is Winnicot's true self (1960), which is a sense of self based on spontaneous authentic experience by contrast of the false self, that is for Winnicott a defensive façade. Also, Wolstein's (1987) concept of the psychic center of the self is similar to the concept of the Adult Self. Wolstein proposed an enlarged picture of the human psyche as fundamentally 
proactive in nature. The psychic center of the self designates the inborn, individual psychological point of origin of all experience and action. I share his definition of the patient as coparticipant in the therapy. However, in severely traumatized patients, we must strive to find the delicate balance between giving our patients the power to make life decisions and helping them make decisions that are beneficial to them.

Kohut's (1991) ideas regarding the destiny of the self or the central program, considers that there is a "nuclear program" that moves the person in the direction of self-actualization. The urge toward wholeness is, for Kohut, more central than our instincts. In my concept of the Adult Self, there is a kind of optimism about a natural tendency of each individual toward self-care and self-regulation, which however, under adverse circumstances, could revert to bad choices. This last tendency can be modified in therapy, retraining this Adult Self to act in the benefit of the patient even in the more difficult situations.

Fonagy and Target (1997) note that interactions which link perceptions, thoughts and emotions as causes and consequences of action, and the contemplation of mental states without fear, contribute significantly to self-agency. They dedicated much of their work in mentalization therapy to promote reflective thinking. Reflective thinking and metacognitive processes are important aspects of the Adult Self.

In severely dissociative patients, working from the Adult Self determines how the therapist interacts with the patient's internal system. The therapist never promotes direct communication with the dissociative part; all communication is directed to the Adult Self who then translates the message to each dissociative part. Even in patients without a central self that is capable of carrying out this role of mediator, we should always enhance the patient's ability to do so.

In the vignette of a patient with severe DID that follows, the readers can see my approach. Here I $(\mathrm{T})$ am working on differentiating the feelings and opinions of the patient's mother from the patient's own:

P: I grew up with my mother and took her values... When I see it...

T: When you see it, your child parts may be activated. You, as an adult, can see your mother as just one more person, but this is not so easy for those parts of you that feel as children who need a mother.

P: I can't see my mother as a person, it's my mother...

T: It could be helpful calling your mother by first name. What she says is what Kathy [the real name of the patient's mother] says, it's not God's word. When they are little, children have no other references about how the world is.

P: I'm not able to see her as a person so the two of us are trapped in this terrible relationship. 
T: Is there any part of you that can see her as a person?

P: No, I see her as a mother... the one who commands, the one who orders...I have something in there that keeps me from seeing her differently.

As the patient is presenting difficulties in having a realistic view of her mother, I propose doing an exercise (Litt, 2007; Gonzalez, 2019), pushing against a wall, imagining that it separates her mother's mind, emotions and opinions from hers. I include bilateral stimulation to reinforce the changes.

T: Imagine the limit, you are Claire, you have your own mind, your ideas, your opinions. There's the boundary on the wall (tapping).

The patient's main personality (one of the apparently normal parts presenting this day in the session) cannot change her perspective, but I suggest a more adult view of her mother, as a human being, not as a symbolic figure. As I introduce that possibility, the patient can start making the change.

P: I feel like I'm falling,

T: Note where she ends and where you start.

P: Yes, we are two different people...

T: Claire is Claire, Kathy is Kathy (tapping). What do you notice?

P: I feel a little girl inside.

T: There's a part of you that feels as a little girl who needs a mom. Let the adult you are tell her that she's grown up, that Kathy took care of you when you were little, but now you've grown up, you're learning how to take care of yourself.

While I am talking, I place my hand on my chest; this is an exercise of taking care of sensations. Mirroring my gesture, the patient imitates it, taking care of the child part.

T: Sometimes you do this as Kathy did for you; you're learning.

P: I feel like there is independence for both of us [her and her mother]. It's very rare, we're not the same.

T: But that's reality, people may bond and at the same time feel as different people. Then it makes sense that one person may have emotions and perceptions that are different from the other's. On the other hand, there are people who merge completely. They think that, for others to love them, they must think the way they think... It is healthier if two people have their autonomy and respect each other.

P: It's hard to understand; and what's going to happen to her [her mother]? 
T: You're going to screen Kathy's opinions from yours. The girl inside you sees Kathy as her mother, with a girl's eyes. But now you have a new option, the hand that takes care of you [reminding her of taking care of the child part].

P: She's her, and I'm me. I feel like I'm getting a divorce.

T: But after this divorce, you'll work better with your mother. Being fussed meant you couldn't stand her presence for long. If you do this [I put my hand on my chest] it won't affect you so much. YOU [the Adult Self] look at your little girl inside and you can say: "I feel my own feelings, I take care of myself, I value what it is appropriate to do."

P: Well... I will practice feeling her [mother] as separate [hand on her chest]. It's very difficult, but well, everything that we practice we learned [we have done much psychoeducational work on the importance of experimentation and the value of learning from mistakes]. I always thought there's only one way to get things done... . but there are more...

In another example, the patient drew her internal system inside a circle. The drawing represented her inner child part and her boyfriend (see Fig. 1).

I explained to her that her boyfriend is not part of her, and I suggested drawing him outside the circle. To take care of the little girl, I suggested drawing the adult she is in the circle (see Fig. 2).

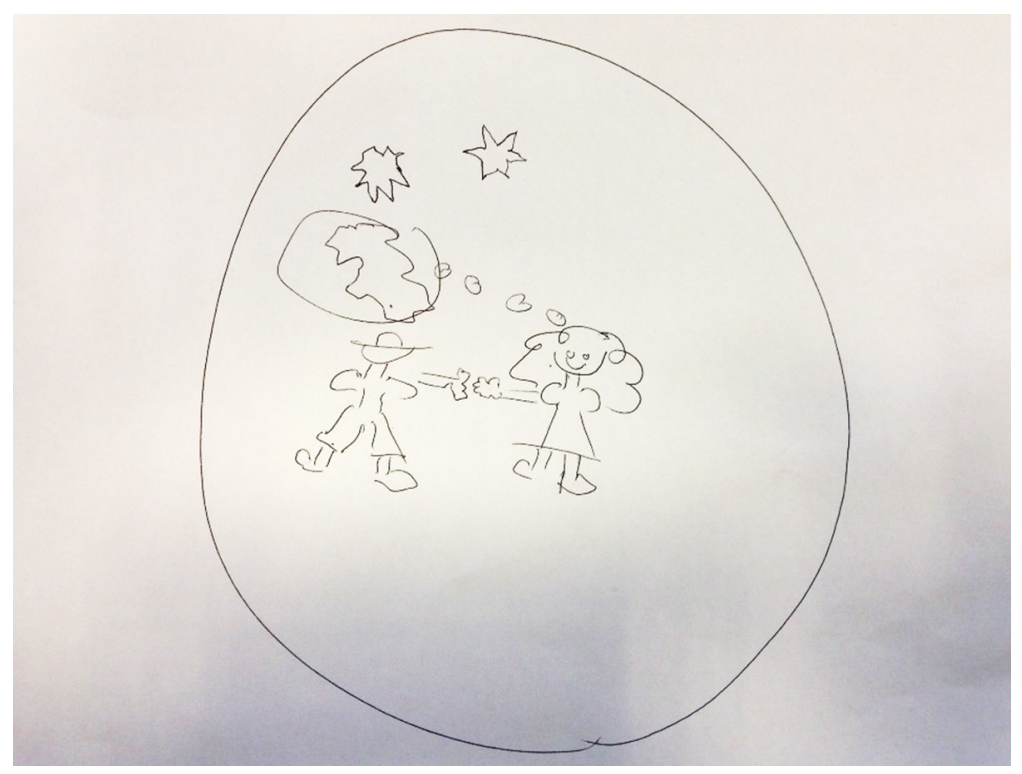

FIGURE 1 


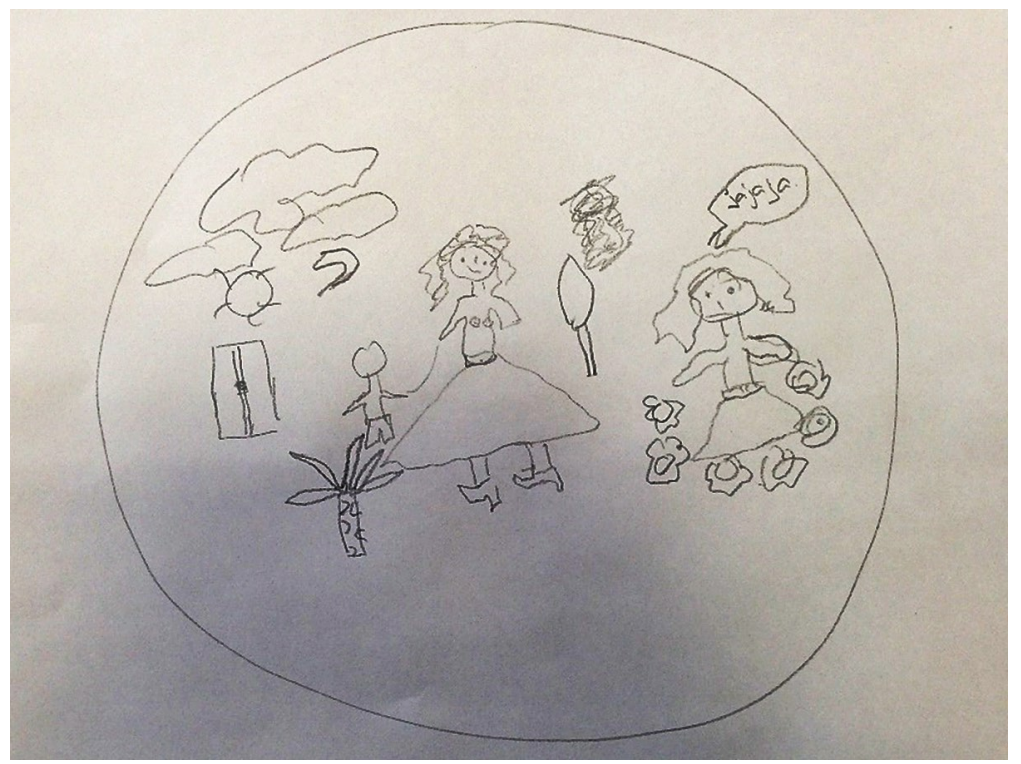

FIGURE 2

P: I don't know how to take care of the little girl.

T: You can learn, that's the point.

She was very reluctant to do it, and we explored the origins of that resistance. When she was a little girl, she had responsibility for the care of older people, duties beyond her abilities for that age; so now, she wanted others to take care of her, and neglected her self-regulation and self-care. Having understood the origins of this pattern, I could question it and talk about it, and the patient was able to introduce the adult she is in the drawing.

In further sessions, processing those memories of excessive responsibility in childhood, was very helpful to change this pattern.

This approach of enhancing the Adult Self of the patient goes beyond dissociative disorders. Working from the Adult Self is also important in doing therapy with people with complex traumatization and attachment disturbances. We must promote our patients' ability to become observers of their mental processes and learn how to modify them. Herman (1992) stressed the relevance of "returning the survivors the power others have taken from them."

\section{WHY OUR PATIENTS LACK A STRONG ADULT SELF}

Patients may be tethered to many feelings and sensations from their childhood or from later stressful experiences. They may cling then to certain maladaptive beliefs about themselves and the world. Our ability to manage 
adversity in early childhood is very limited. When we were children, we depended on those who cared for us to realize what was happening to us and do what was necessary to solve it. If our caregivers did not realize what was happening or chose not to do anything about it, we had no choice. But when we become adults, we always have options.

It is likely that our patients do not see what their options are. Sometimes this is because they think that options are not plausible. They try to solve their problems by avoiding, for example, imagining that they move to a deserted island where no one bothers them. In fact, they have no island to go to, and when they realize this, they fall further into despair. They do not consider small, practical solutions that are possible in the medium and long term, which really bring about change.

Even when options are evident to the patients, they act as if trapped and helpless. Those feelings were justified in childhood, but reality is different here and now. Even if they still live with the family of birth or in an old, problematic relationship, it is now possible to take initiative for change. If we can help them be more aware that they are adults and they are in the driver's seat, their perspective takes a radical turn. They will know that solving their problems depends on them, so they will take the reins and assume responsibility.

Our patients may feel much discomfort when we share these reflections with them, but it is essential for moving forward. Perhaps, they can think, "It's not fair-how can it all depend on me? Others owe treating me better. How can I be okay if my parents, my husband, my boss, or my children all treat me this way?" To that, the answer is yes, we can do better, although others remain the same. Luckily, in every relationship, we can always contribute our $50 \%$ for change. That gives us a sufficient margin to change things.

Even when our patients do not consider themselves to be capable of taking care of themselves, to self-regulate, and to take responsibility of their recovery process, we ourselves must be confident in their capacities to do this. However, at the same time, it is important not to force them beyond their current abilities. As a good enough parent, the therapist has to be confident in the patient's potential to improve without asking of them more than their developmental level allows. We must understand the patient's helplessness and insecurity as dysfunctional beliefs and help them to change these beliefs toward a new narrative.

Our patients might think, "But how is that possible? My mother still treats me like a child." And that is when we remind them that they are now adults even if others treat them like children. If they allow the adult, instead of the child left locked inside them, to talk to their mother, still aware of the childhood feelings in them, that conversation is going to turn out very differently. The change begins when our patients cease waiting for someone else to come and free them from their past. 
Sometimes, when people endure adversity for a long time, they dream of a rescuer who ends it or a genie who grants them three wishes. They may fantasize discovering that they do not actually belong to this family and that their real parents suddenly appear, or that they move to another country. The imaginary solution may be that one day they find a love that gives them everything that they have been denied, or to become a parent who provides everything they themselves missed as children. Fantasizing is an escape, and above all during childhood, fantasy is a powerful resource that allows them to disconnect from things that they cannot change. However, as adults, our patients cannot wallow in fantasy, waiting for someone to rescue them from themselves. Real solutions will not come as the dramatic shift that they imagine. They can do something concrete, perhaps small, but real. Thousands of small changes move the world. To do this, they must change their perspective.

\section{RETRAINING THE MIND}

An important expression of self-care and self-regulation is the way in the patient talks to themselves. What patients say to themselves internally may come from what caretakers in the patient's history said in the past, and from difficult times later, when they had to push themselves ahead with nobody there to help them. This internal self-talking is usually dysfunctional in severe traumatization; in more dissociative presentations, it takes the form of voices or egodystonic thoughts that resemble how relevant figures from the patient's history spoke.

It is important for our patients to be aware of the way they are talking to themselves. This internal dialogue is very important in the regulation of their emotions and can either attenuate and modulate emotional states or become an echo chamber that multiplies their intensity. Becoming aware of this internal dialogue and introducing changes is essential for our patients' improvement. I have labeled this type of work as cognitive self-care (Gonzalez, 2019). They must switch from automatic to manual and help their minds turn from what they tend to say to what will help them more. When a patient presents very autonomous dissociative parts, this idea of changing the internal dialogue can be a more normalized way of talking about dissociative parts. Of course, this is not all we need to do in therapy, but in my experience, it may be a good starting point.

For change to happen, our patients should re-train their mind. It is essential for them to understand where the problem is, but that is only the first step. They must exercise it regularly until a new way of talking to themselves is so internalized and becomes natural. In the meanwhile, they must be alert and deliberate with this training to make sure it is advanced and consolidated. I propose my patients do an exercise for changing selftalking that they must do on a daily basis. This mental exercise consists of a 
sequence of questions which we must present in order. Although patients may already know the answer, the questions must be asked and answered every single time. The power this change has on improving one's well-being is great, although our patients may notice it only after a time.

Initially, the patient may claim they do not say anything to themselves because their thoughts can go unnoticed if they do not pay attention to them. When they feel bad, they may be aware only of their distress but not of their thoughts. We can then suggest to the patient to stop for a while and observe or give an explanation about what people usually say internally when they feel bad. If a person in distress says, for example, "I can't stand feeling like this," "I'm an idiot for allowing this to happen," "It's all my fault," "I'll never get out of this" or "I wish I were dead," their distress will get worse. These phrases are not merely consequences of emotional distress, but they will generate new negative sensations or worsen the ones already present. If we help patients pay attention to these negative judgments, we can then help them reflect and practice the next exercise.

\section{These Are the Questions That Our Patients Must Contemplate:}

What am I saying to myself?

Our thoughts can go unnoticed if we do not pay attention to them. When our patients feel bad, they may be unaware only of their distress, not of their thoughts. Usually they tell themselves something about why they are distressed. For example, "I can't stand feeling like this," "I'm an idiot for allowing this to happen," "It's all my fault," "I'll never get out of this" or "I wish I were dead." These phrases are not simple consequences of their emotional distress, but they will generate new negative sensations or worsen the ones already present. It helps to write these phrases down, word for word, while they say them to themselves. Seeing them on paper can make them more aware of the number of insults that they inflict on themselves and how they discourage or discredit themselves internally.

\section{Where did I learn this?}

These phrases often replicate what the person heard from significant figures in their lives. Their parents, teachers or partners may have said, "You're unbearable," "You're an idiot," "It's all your fault," "You're unfixable," or "You never should have been born." As I explained above, the way in which people talk to themselves internally mirrors how important figures from their past talked to them. They see themselves as others saw them and treat themselves as others treated them. At other times, it was not any person who said those things to the patient, but they started to put pressure on themselves in order to overcome difficult situations. We explain to the patient that the problem is that once we internalize that model, we carry 
it with us. We cannot get away from ourselves, despite trying to do so in a thousand ways. Our head is on our shoulders 24 hours a day. We have no choice but to reprogram our mind.

\section{Did it help me when those people said it to me?}

It is obvious that no one likes others telling us that we are unbearable, a mess, guilty or worthless. It is furthermore important for the patient to notice how badly those statements made them feel, how destructive they were and how, from the very beginning, they stirred up uncomfortable feelings. This was the air that they breathed in those relationships, and if they stop to think about it, they surely will consider this to be a legacy that they do not want to hold on to.

Would it help me if the people who are around me now said the same things?

We propose the patient to imagine saying to someone, "You won't be able to handle this," "You're an idiot for feeling this way," "It's your fault that you're in this situation," "You aren't going to improve" or "You'd be better off dead." We ask them how they would feel if all this was said to them. The patient has to ask themselves this question and answer it. It will make them aware of what it means when they do the same internally, repeatedly. When they stay home, seeing no one, often they find no rest, as they are their own worst enemy.

Would I say that to a loved one who matters to me?

In order to help the patient to realize how dysfunctional those phrases are, we ask them to think of saying it to their loved ones, their best friend or their children. Supposing they are feeling exactly like the patient is, they have to imagine themselves saying to those people: "You won't be able to handle this," "You're an idiot for feeling this way," "It's your fault that you're in this situation," "You aren't going to improve" or "You'd be better off dead." Obviously, it feels aberrant and is unthinkable for them to do so. It is important that our patients become aware of the terrible things that they tell themselves. That change is an important step toward ending that problem.

What would be helpful to say to myself instead?

We remind the patient that, if we are working on improving our emotional state, searching for what is good for us must be our first priority. It would be good to tell themselves that they will be able to deal with this adversity, that it can happen to anyone, and that they did the best they could do. They could tell themselves that, with time, everything passes, that it will be hard, 
but they can move forward, that they are important, and that they deserve to feel good.

It is possible that our patients themselves do not believe what they say, but it is necessary to stress to them that feeling what they say is true should not be the most important thing. If a friend feels bad for being overweight, we do not say, "You're fat!" Similarly, when our patients constantly remind themselves of their mistakes and bad feelings, they are just fueling their malaise. It is like they are digging themselves into a deeper hole. If they want to get better, it is important for our patients to learn to say to themselves what actually makes them feel better. It does not matter if they believe it or not, or if it sounds weird. If they have spent their life crushing themselves internally, it will feel strange to treat themselves right; in fact, it will feel almost alien. But if they keep repeating the new model of internal dialogue, it will end up sounding more natural. In a way, it is like learning a new language. First, they repeat the words mechanically, saying the same phrases again and again, until their brain begins to assimilate and remember them. They will not be fluent in that language for a long time, but this is the normal learning process.

In order for our patients to maintain this learning process until it works, we must show them the path and how a realistic change takes place. I use the video The Backwards Brain Bicycle (Sandlin, 2015) as a metaphor of how things work when we want to change a chronic pattern. This video makes a lot of sense for our patients in the group session. Learning to selfcare and self-regulate-instead of blaming themselves and dysregulating emotions-is like unlearning to ride a backwards bicycle and then learning to ride a normal one. I also created a video with all the steps that I described above (Gonzalez, 2019) because it is easier for patients to see a video and follow the steps than try to think about it or do written homework.

The adult who is inside our patients must learn to understand their emotions and take care of their needs. We help them to realize how their early caregivers regulated the patient's emotions, while we remind them that they are adults capable of learning a new way of regulating their own emotional states and their mental functioning.

For doing this work, our conceptual reference is safe attachment. A caretaker who understands that a child's discomfort has to do with being hungry, sleepy or sick provides what is good for the child, what is really needed. Although our patients did not have this learning experience earlier, they can still create it now. The adult they are now must be in charge of that process. They do not need to know how to do it-they must just try with our guidance. It is true that in order to learn to drive someone has to teach us. It is important to stress to our patients that they are not alone in this process. It is essential that they get in the car, take the wheel, and take control of their lives. 


\section{REFERENCES}

Fonagy, P., \& Target, M. (1997). Attachment and reflective function: Their role in self-organization. Development and Psychopathology, 9(4), 679-700. doi:10.1017/S0954579497001399

González, A. (2018). It's not me: Understanding complex trauma, attachment and dissociation. Seattle, WA: Kindle Direct Publishing.

González, A. (2019). EMDR and emotional processing: Working on severely dysregulated patients. Seattle, WA: Kindle Direct Publishing.

González, A., \& Mosquera, M. (2012). EMDR y disociación: el abordaje progresivo. Madrid: Pléyades. [English version: EMDR and Dissociation: The Progressive Approach. Seattle, WA: Kindle Direct Publishing.

Gonzalez, D. (2019, March 21). Learning Self-care-Trauma, attachment, dissociation [Video file]. Retrieved from https: / / www.youtube.com/watch?v=iP6X0p8CLWo\&t=106s

Herman, J. L. (1992). Trauma and recovery: The aftermath of violence-From domestic abuse to political terror. New York, NY: Basic Books.

Kohut, H. (1991). The search for the self: Selected writings of Heinz Kohut: 1978-1981, Vol. 4 (P. H. Ornstein, Ed.). Madison, CT: International Universities Press, Inc.

Litt, B. (2007). The child as identified patient: Integrating contextual therapy and EMDR. In F. Shapiro \& F. W. Kaslow (Eds.), Handbook of EMDR and family therapy processes (pp. 306-324). Hoboken, NJ: John Wiley \& Sons.

Sandlin, D. (2015, April 24). The backwards brain bicycle-Smarter every day 133 [Video file]. Retrieved from https:/ / www.youtube.com/watch?v=MFzDaBzBlL0\&t=1s

Seligman, M. (1975). Helplessness: On depression, development, and death. New York, NY: W. H. Freeman/Times Books/Henry Holt \& Co.

Winnicott, D. W. (1960). Ego distortion in terms of true and false self. In Winnicot, D. W. (Ed), The maturational process and the facilitating environment: Studies in the theory of emotional development (pp. 140-152). London, United Kingdom: Karnac Books.

Wolstein, B. (1987). Anxiety and the psychic center of the psychoanalytic self. Contemporary Psychoanalysis, 23, 631-658.

Young, J., Klosko, J., \& Weishaar, M. (2003). Schema therapy: A practitionerÂt's guide. New York, NY: Guilford Press. 